\title{
ARTHROSCOPIC TREATMENT OF MENISCAL CYSTS
}

\author{
J. M. PASSLER, H. P. HOFER, G. PEICHA, R. WILDBURGER
}

From the University Clinic for Surgery, Graz, Austria

In a series of 1160 arthroscopies we found 16 meniscal cysts; 12 involved the lateral joint line and two the medial, and two were intra-articular. In all but two cases, arthroscopy showed meniscal tears.

We recommend arthroscopy of all cases to correct the meniscal lesion, and to evacuate the cyst into the joint by opening the joint capsule. This was successful in 12 cases, with no recurrence after an average follow-up of 18 months. Only two patients with no meniscal lesion on arthroscopy required an additional external incision for cyst removal.

J Bone Joint Surg [ Br] 1993; 75-B:303-4.

Received 21 October 1991; Accepted 15 May 1992

Cysts of the menisci are well known but their cause remains controversial. Mucoid degeneration of the menisci has been blamed (Jaffrés 1975; Romanini et al 1988), and connections between cysts and degenerative areas have been shown by the use of contrast material
(Müller 1982). Other studies suggest that these cysts may result from infiltration of joint fluid through minute or larger tears (Seger and Woods 1986), and emphasise the concurrence of meniscal tears and cysts (Beaufils, Ceolin and Perreau 1988; Reagan et al 1989). Most meniscal cysts are related to the lateral meniscus.

\section{PATIENTS AND METHODS}

In a series of 1160 arthroscopies for all indications, 16 knees were found to have a meniscal cyst. In 14 the cyst was palpable outside the joint, 12 on the lateral and two on the medial side (Fig. 1). In the other two patients an intra-articular extrameniscal cyst was found unexpectedly during arthroscopy for recurrent locking (Fig. 2). Eight of the 14 patients with palpable cysts also had typical symptoms and clinical signs of meniscal lesions, but the other six had no symptoms of internal derangement. In four of these six we found a completely

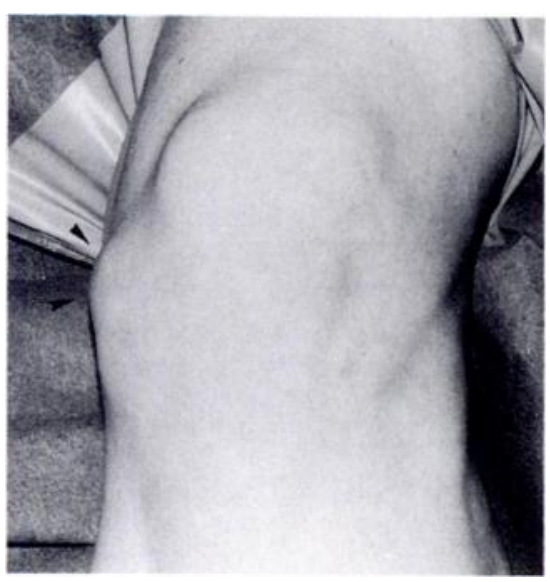

Fig. la

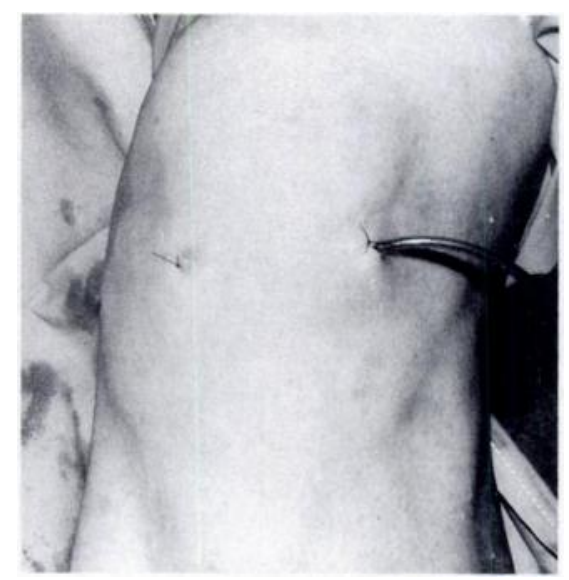

Fig. 1b
A medial meniscal cyst of the left knee (arrowheads), before (a) and after (b) arthroscopic treatment.
J. M. Passler, MD, Consultant Trauma Surgeon

H. P. Hofer, MD, Consultant Trauma Surgeon

G. Peicha, MD, Junior Trauma Surgeon

R. Wildburger, MD, Consultant Trauma Surgeon

University Clinic for Surgery, Department of Traumatology, Auenbruggerplatz 1, A-8036 Graz, Austria.

Correspondence should be sent to Dr J. M. Passler.

(C) 1993 British Editorial Society of Bone and Joint Surgery 0301-620X/93/2477\$2.00 degenerated meniscus, and the other had two stable horizontal meniscal tears. In only two patients was there no arthroscopic evidence of a meniscal lesion.

Technique. For radial lesions we perform partial meniscectomy, but we do not resect stable horizontal lesions. We then open the joint capsule from the inside, to allow the contents of the cyst to drain into the joint. In the presence of a horizontal tear it was possible to open the 


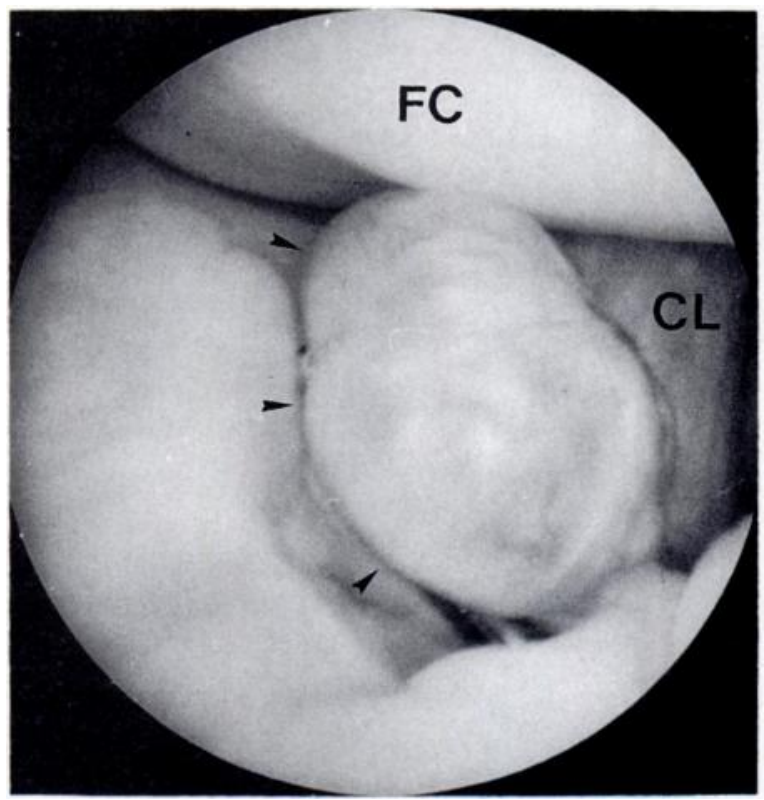

Fig. 2

An intra-articular cyst of the lateral meniscus (arrowheads), shown in relation to the lateral femoral condyle (FC) and the anterior cruciate ligament $(\mathrm{CL})$.

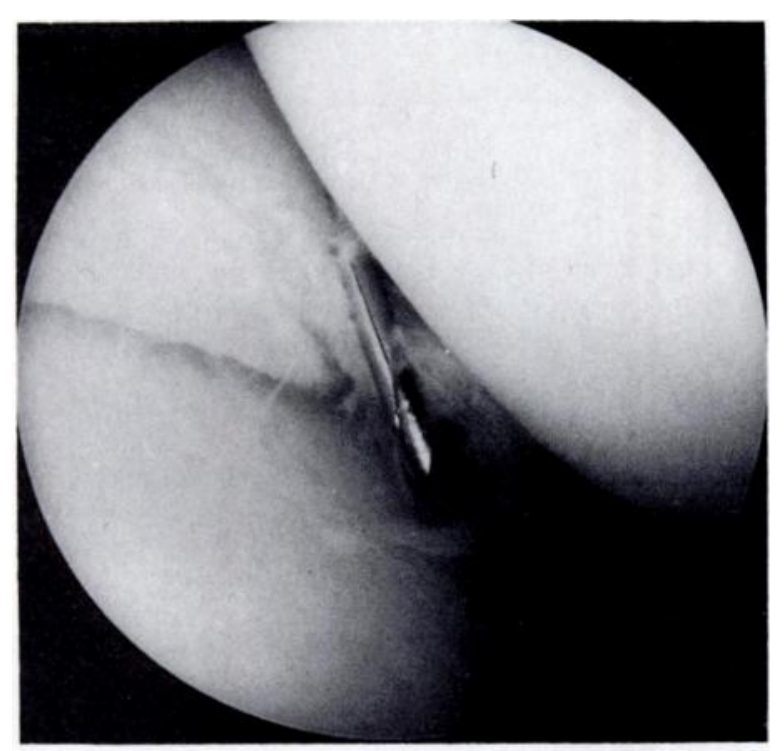

Fig. 3

Horizontal and radial tears of a medial meniscus. The needle has been pushed through a meniscal cyst into the joint, to mark the exact position for arthroscopic opening of the capsule.

joint capsule between the two meniscal fragments, after marking the exact area by a needle pushed from the outside, through the palpable cyst (Fig. 3). In the two knees with no meniscal damage, drainage of the cyst into the joint space was not achieved arthroscopically. In these, the cyst was excised from outside the joint, and in both cases there were small cystic degenerative areas in the mid-substance of the base of the meniscus.

The two patients with intra-articular cysts were treated by a simple arthroscopic resection; in one of them this produced detachment of the anterior horn of the lateral meniscus, which required arthroscopic repair.

\section{RESULTS AND DISCUSSION}

We diagnosed meniscal cysts in only 16 of 1160 patients having an arthroscopy (1.4\%), and two of these were intra-articular. We could find only one report of a similar case : Stern and Hallel (1988) described an intra-articular cyst arising from a discoid medial meniscus in a nineyear-old boy. After eight months to three years (average 18 months), we have seen no recurrence of cysts in our 16 patients. We therefore consider that meniscal cysts should always be treated by arthroscopic methods, even in the absence of any evidence of internal derangement.

The advantage of an arthroscopic procedure is that limited partial meniscectomy can be combined with drainage of the cyst into the joint. It is important to check the stability of the meniscus after resection, especially when the cyst was in the peripheral base of the meniscus. If there is any instability, the meniscal base should be refixed by an arthroscopic suture technique.

No benefits in any form have been received or will be received from a commercial party related directly or indirectly to the subject of this article.

\section{REFERENCES}

Beaufils Ph, Ceolin JL, Perreau M. Medial meniscal cysts: a report on 32 cases. Proc 3rd Congress of the European Society of Knee Surgery and Arthroscopy, Amsterdam, 1988:18.

Jafirés R. Les kystes méniscaux, considérations thérapeutiques et pathogéniques. Rev Rhum Mal Osteoartic 1975; 42:519-26.

Maller W. Das Knie. Berlin, etc: Springer-Verlag, 1982:115-7.

Reagan WD, McConkey JP, Loomer RL, Davidson RG. Cysts of the lateral meniscus: arthroscopy versus arthroscopy plus open cystectomy. Arthroscopy $1989 ; 5: 274-81$.

Romanini L, Calvisi V, Collodel M, Masciocchi C. Cystic degeneration of the lateral meniscus: pathogenesis and diagnostic approach. Ital J Orthop Traumatol 1988; 14:493-500.

Seger BM, Woods GW. Arthroscopic management of lateral meniscal cysts. Am J Sports Med 1986; 14:105-8.

Stern A, Hallel T. Medial discoid meniscus with cyst formation in a child. J Pediatr Orthop 1988; 8:471-3. 